Fecha de recepción: marzo 2012 Fecha de aceptación: junio 2012

Versión final: marzo 2013

\section{Los aportes de la creatividad ante la dificultad reflexiva del estudiante universitario}

Eduardo Vigovsky *

\begin{abstract}
Resumen: Los estudiantes universitarios encuentran cada vez mayores dificultades en analizar, comprender, relacionar y sintetizar.

Los alumnos toman por cierto todo lo que figura en internet y lo dan por válido sin un espíritu crítico, se ubican en una posición de cómodos espectadores.

Los profesores universitarios debiéramos cambiar nuestra manera de impartir docencia, dejando de ser ese gran Otro que nos confiere el alumno.

La creatividad de los alumnos universitarios representa un reto profesional y una posibilidad de crecimiento personal de enorme valor humano.
\end{abstract}

Palabras clave: comunicación - conocimiento - creatividad - docencia.

[Resúmenes en inglés y portugués en la página 205]

(*) Psicólogo. Dicta cursos de creatividad e inteligencia emocional, con técnicas teatrales en el Centro Rojas de la UBA. Es docente de la Facultad de Diseño y Comunicación de la Universidad de Palermo en la carrera de Relaciones Públicas.

He observado con atención en mi experiencia docente que los estudiantes universitarios encuentran cada vez mayores dificultades para analizar, comprender, relacionar y sintetizar. En este sentido, no pocas veces, por ejemplo, cuando se plantea una cuestión a un estudiante, su contestación refleja, bien que no ha entendido la pregunta, bien que no ha comprendido su objeto fundamental.

He participado como profesor adjunto en varias mesas de examen de la Universidad de Palermo, donde dicto la materia; "Comunicación grupal“, en la carrera de Relaciones Públicas. Los alumnos se presentan a rendir diversas materias por lo general en el área de diseño, de modas, de interiores con excelentes producciones: Dibujos brillantes, colecciones de moda, magazines, pero en el momento que el profesor titular de la materia o algún adjunto le preguntan al alumno sobre la teoría de lo que presenta, que reflexione sobre el proceso de su propio trabajo, en ese momento, el alumno se traba, se confunde, se pone nervioso, falla. Y cuando se les muestra su desconocimiento, frecuentemente la respuesta es "sí lo sé, pero no sé cómo expresarlo".

Esta preocupación en aumento, excede los claustros, tan así es que el diario Clarín de Buenos Aires, saca un extenso artículo el 29 de diciembre del 2011 donde la Lic. Gloria Gitaroff opina: 
"La palabra es un medio de expresión de necesidades y sentimientos, es una forma de comunicación y, también, es la herramienta que nos permite pensar y adquirir conocimiento" (Clarín, 29 de diciembre 2011).

Actualmente la presión que proviene del lenguaje informático, donde pareciera que la retórica, el arte del buen decir fuera un estorbo, frente a la economía que imponen el Twitter o el SMS, donde cualquier detalle o intento de precisión se desechará y el placer de compartir la belleza del idioma quedará descartado.

Por otro lado, el escritor español Juan Cruz Ruiz se expresa del siguiente modo:

Se habla menos, se dice menos, los mensajes telefónicos, la costumbre veloz del mail, la irrupción del lenguaje basura en la conversación cotidiana, el traslado de lo verbal a lo escrito, han herido hasta la sangre el lenguaje literario o narrativo (Ruiz, 2011).

A mediados de este mes, en una conferencia internacional, Nicholas Car reflexiona: "En el mundo de Google hay poco lugar para el silencio reflexivo de la lectura". Varios son los científicos que estudian la influencia de Internet en el proceso de razonamiento humano. De acuerdo con un estudio de la Universidad College de Londres llamado: 'La revolución virtual - Homo Interneticus", la Web está erosionando la capacidad de controlar los pensamientos, debido a que modifica el cerebro. "Internet alienta la multitarea y fomenta muy poco la concentración, desincentiva el pensamiento profundo, logra que nos desentendamos del pensamiento crítico acerca de lo que está haciendo Internet, porque dedicamos todo el tiempo a picotear informaciones en esta Red".

En la actualidad, existe más información disponible que nunca, pero cada vez hay menos tiempo para hacer uso de ella, el cerebro puede tener dificultades para procesar esa avalancha de datos publicados en la web.

Con el uso de Internet la sociedad conforma de modo distinto el vínculo con los otros, genera una nueva forma de afectividad y otro nexo de los individuos con su corporeidad, una corporeidad virtual. Ahora el cuerpo que predomina socialmente es el virtual, el que se exhibe a través de la tecnología, no el que verdaderamente se tiene: con el que se respira, se come, se camina y también se padece. Pues no hay psique sin cuerpo, no hay pensamiento subjetivo sin cuerpo. En cambio, en nuestra sociedad, también llamada de la información, las tecnologías y la comunicación son el eje donde se está generando la nueva emergencia y construcción de subjetividades.

En el Segundo Congreso Latinoamericano de Enseñanza del Diseño, organizado por la Universidad de Palermo el año pasado, he coordinado una de las mesas donde se ha observado: Con respecto a los alumnos: Nos encontramos que tienen un lenguaje particular, que son nativos digitales. Incluso hay estudios que determinan que hay cerebros digitales y cerebros analógicos. Los alumnos toman por cierto todo lo que figura en internet y lo dan por válido sin un espíritu crítico.

En promedio los graduados universitarios (especialmente en los EE.UU. pero crecientemente en todos los rincones del planeta) han pasado cerca de 5.000 horas de su vida leyendo, pero cerca de 10.000 horas jugando a videojuegos y cerca de 20.000 horas viendo TV. Han pasado toda su vida rodeados de computadoras, videogames y el resto de los gadgets digitales. Serán los productores de todo lo que se inventará en el futuro. 
En este proceso civilizatorio que se está conformando, se están dando cambios muy acelerados en la manera como percibimos y concebimos nuestro presente, pasado y futuro, al igual que en la forma en que sentimos y comprendemos nuestro entorno y nuestra relación con los otros. Estamos gestando una nueva cultura, una nueva civilización y una nueva subjetividad, aunque no nos percatemos de ello.

Entre tanto bombardeo de información, se pierde el tiempo y la capacidad para la reflexión. No hay tiempo para la reflexión entre la información y la acción, lo que a su vez provoca una pérdida de capacidad para expresar y poner en palabras lo que sentimos.

Los principales obstáculos o bloqueos psicológicos provocan perjuicios en todas las áreas vitales y, en especial, en el proceso de toma de decisiones. Son inconscientes, generalmente, actúan juntos y se nutren unos a otros lo cual, no obstante, trae la ventaja de que al superar uno o varios de ellos se puede enfrentar a los demás.

De esta manera, se cae en un estado de alexitimia, que es la discapacidad para expresar lo que se siente y piensa. En otras palabras, no habrá capacidad para medir o reflexionar anticipadamente sobre la consecuencia de los actos.

Al perder la capacidad y el tiempo para reflexionar sobre las propias acciones y las del otro, se pierde la capacidad de empatía. Aquí donde surge la intolerancia, la falsa convicción de que el respeto empieza y termina en uno mismo, imposibilitando así la consideración del otro en su diversidad de acción y pensamiento.

\section{La realidad como contemplación del espectáculo}

Algunas reflexiones acerca de este panorama desalentador.

Tanto es así que podemos decir, pues somos seres parlantes y esta posición del ser hablante, nos comienza a diferenciar de esta posición paradigmática de la modernidad que muestra la realidad como un espectáculo a contemplar sin la necesidad de decir nada al respecto.

Preparando este trabajo, me encuentro, lo cual es maravilloso que uno buscando siempre se encuentra, que hay un conjunto musical peruano llamado Libido. Este conjunto presenta un tema musical llamado Hablar no es necesario

Alguien te quiso seguir, sabes lo que quieres con él

Alguien ha encontrado al fin el amor que estaba al lado

Él te busca para un sí, algo guarda en un rincón

pronto te lo va a mostrar, él tiene un acento extraño

\section{Hablar no es necesario}

Hay un hueco en la pared, por si alguno quiere ver lo que hay en la oscuridad, él tiene un aspecto vano toma el tiempo para actuar, busca lo que quieres ser el te ha visto sonreír, quizás lo ha estudiado todo 


\section{Hablar no es necesario, hablar no es necesario...}

(Libido, Hablar no es necesario)

Qué paradoja que este conjunto musical lleve el nombre de la Libido, término que Freud en su teoría de la sexualidad, identifica como energía psíquica, fisiológica y emocional, vinculada no sólo con el deseo sexual, sino con todas las actividades constructivas humanas.

\section{La comunicación es un proceso inherente al ser humano}

Acaso este conjunto musical desconoce las exigencias de una sociedad moderna plagada de información, justamente un profesional exitoso deberá seguir estos procedimientos por lo menos en la comunicación de la gestión de proyectos, donde hay que determinar:

Con que grado de detalle: Comunicar propósitos, dar a conocer metas, hacer comprender cómo lograrlas, compartir emocionalmente expectativas y desafíos

Más allá de comunicar, recordar: dar a conocer, hacer comprender, compartir emocionalmente, comprometer y comprometerse, impulsar, cumplir, agradecer y confiar.

Así las cosas, quizás los profesores universitarios debiéramos cambiar nuestra manera de impartir docencia, procurando estimular en el estudiante la pasión por el conocimiento.

El alumno se presenta cómodamente, se apoltrona en su ubicación de espectador, confiriéndole al docente, el lugar del gran Otro, el sujeto supuesto saber, que nombraba Lacan.

Ese es el mismo lugar que la sociedad moderna, con esta particular visión subjetiva, le infiere a internet: "todo lo que vale está en Internet, si no está allí no existe".

En el ya mencionado Segundo Congreso Latinoamericano de Enseñanza del Diseño 2011, nuestra comisión trató especialmente el tema de los profesores, su función y desempeño ante esta nueva era informática

Con respecto a los profesores, se han sacado las siguientes conclusiones

- El profesor no es un computador

- El docente como mediador con la función de anclaje del saber ante tanta invasión de imágenes y tecnologías que aturden y confunden al alumno

- El docente debe adaptar la pedagogía al uso de las nuevas tecnologías .Debe explicitar las competencias específicas y generales requeridas y esperables por él para aprobar la asignatura

El docente Universitario no debe caer en este paradigma moderno que nos pone de observadores, donde hablar no es necesario; el hombre es un ser hablante por naturaleza, sería imposible no tener nada para decir o no poder decir nada acerca de algo.

Ya la Biblia nos advierte de esta particular manera de contemplación del mundo. Si hacemos un parangón y situamos al profesor que imparte clases magistrales como a un Dios todopoderoso y, al alumno como un obediente feligrés, podemos leer de este modo el párrafo bíblico del diluvio. Dios le advierte a Noé sobre el advenimiento de un diluvio, le da una clase magistral, le indica lo que deberá realizar, los animales, que deberá subir al arca, las medidas de la misma, en fin Dios se presenta como un profesor magistral. Y fíjense qué interesante, ¿qué le dijo Noé ante semejante manifestación? Nada parafraseando al grupo Libido "hablar no es necesario". Nada dijo de sus sentimientos, de sus emociones, de la sensación de ver un mundo conocido bajo el 
agua, solo presentó su portfolio en tiempo y forma y el profesor le puso un 10.

Sobre la previsión paradigmática, podemos hacer algunas observaciones, que siempre serán conjeturas, solo un estudio prospectivo serio, puede determinar algo sobre el futuro de la educación, más allá de que estamos atravesados por la incertidumbre.

Sin más hasta hace pocos años se pronosticaba que los jóvenes, ante el hecho cierto de que estaban poco motivados para la lectura y la escritura, que poco a poco los jóvenes dejarían de escribir.

Sin embargo, los jóvenes escriben, confeccionan, leen e inventan más que nunca en la historia de la humanidad, con los mensajes de textos y los no tan jóvenes también, libros enteros, tratados llenos de una lengua rica en síntesis y nuevas morfologías de la lengua

Diego Tapia, neurólogo, dice: “Internet es una herramienta útil”. No considero que Internet influya en nuestra capacidad de concentración. Tampoco estoy de acuerdo en que al aprovechar la tecnología que ofrece la Red, perdamos nuestra capacidad para concentrarnos en una determinada lectura. Usted puede leer libros en Internet.Es una herramienta muy útil.El cerebro tiene, además, una capacidad de aprendizaje inusitada. Aprende al tocar, al ver, al escuchar. Aprendemos no solo de los profesores de la universidad, sino también de lo que nos cuentan los amigos y familiares. Toda información ingresa a nuestro cerebro que solo es aprovechado en un 10\% de su capacidad. Son los jóvenes, hoy apoltronados en sus cómodos pupitres de un aula universitaria, los mismos que protagonizaron el mayo francés, el cordobazo, la revolución islámica, los creadores del faceboock, que hoy manejan millones de usuarios, fueron jóvenes universitarios

Ahora bien, el sistema educativo, que es el instrumento fundamental para transmitir los nuevos progresos, se atrinchera en el aula. La educación dice Coombs, como transmisora, y creadora de conocimientos ha fracasado, si bien exhorta al cambio a los demás, ella parece renuente a la innovación en sus propios asuntos

Entonces la Universidad persuadida de este panorama, no puede hacer caso omiso a este desafío del siglo XXI, debe ofrecerle a estos jóvenes creativos nativos de la informática, un espacio óptimo para su desarrollo.

\section{Un ambiente propicio para lograr la tendencia creativa}

La creatividad in crescendo de los alumnos universitarios y más aún de los que acceden al diseño y la comunicación, representa un reto profesional y una posibilidad de crecimiento personal de enorme valor humano y convierte al proceso en búsqueda, exploración y hallazgos. Por ello, educar en la creatividad es educar para ser capaces de afrontar las diferentes situaciones personales y profesionales con las que los estudiantes universitarios se encontrarán a lo largo de su vida. La creatividad será entendida como competencia transformativa, autónoma y generativa de la persona, en interacción con sus entornos, con impacto altamente significativo en las habilidades para aprender.

El pensamiento creativo permite alternar el pensamiento lineal y convergente con lo alterno y divergente, posibilitando un nuevo aprendizaje.

El pensamiento divergente, caracterizado por fluidez, flexibilidad y elaboración, propicia el entrenamiento y el desarrollo del pensamiento y el aprendizaje creativo, así como la fluidez. Permitir libertad, promoviendo responsabilidad, para ofrecer opciones de experimentar, pro- 
blematizar y discrepar, permitiendo el desarrollo de la independencia de acción y juicio y el desarrollo de la imaginación.

Se puede organizar a través de dimensiones:

La dimensión persona: Compete todas las características psicológicas del sujeto creativo, incluyendo los factores afectivos, motivacionales y cognitivos, instrumentales, actitud y personalidad además de estudios de casos.

La dimensión producto: Compete a comprender los criterios que hacen, que una obra, objeto o idea pueden ser clasificadas de creativas y los antecedentes que permiten establecer niveles de creatividad o formas diversas que se manifiestan en conducta creadora.

La dimensión proceso: Asume las etapas o pasos que recorre la experiencia creativa, las estrategias, métodos y técnicas de desarrollo creativo.

La creatividad estimula en forma provocativa el hemisferio derecho del cerebro, más perezoso que el izquierdo. Necesita para su desarrollo, el ambiente que se establece frente al espacio lúdico y distendido, donde se reducen las críticas, donde en este proceso, y con la búsqueda de ideas o resultados aun inéditos, es posible atravesar por supuestos imposibles, vender productos invendibles, utilizar el " Como si" del teatro, donde la ficcionalidad permitirá entrar en un juego de roles y de nuevos escenarios posibles, que obligan al alumno a salir de su zona de comodidad y reflexionar sobre los resultados inesperados de las respuestas obtenidas.

Es un trabajo lento pero intenso, comienza con una búsqueda sin resultados específicos, en su primera parte de la elaboración. A la manera del escultor que no sabe con qué se va a encontrar cuando termine de esculpir una pieza de mármol fría y cuadrada, solo sabe que debe sacar, cortar y cincelar, hasta encontrar algo que estaba allí esperándolo.

\section{Competencias a desarrollar}

Fortalecer y estimular características de personalidad tales como la independencia, la originalidad es lo que define el proceso como único o diferente, incluso propio.

Las estrategias más comunes serían: la analogía (capacidad de ver semejanzas no vistas por otros, y empleo de analogías remotas), lluvia de ideas, llevar a cabo transformaciones imaginativas (magnificación, minimización, reversión), enumerar atributos

Trabajar la imaginación es básico para propiciar un pensamiento divergente y creativo. La imaginación puede trabajarse en la formación de imágenes mentales o en la creación de modelos que interpreten la experiencia de una época cultural, ya que el arte es la representación de conflictos y cuestionamientos de los seres humanos, presentados de manera metafórica, alegórica o ficcional. Adaptarse y responder a los cambios producidos por la dinámicas de la vida humana y la realidad social, de modo que le permitan no solo aprender sino también "desaprender" y volver a aprender (auto reorganización).

En cuanto al estilo cognoscitivo (hábitos del procesamiento de la información) se destacan: la detección del problema (centrar la atención en los problemas que deben ser acometidos, considerar 
muchas alternativas, explorar antes de hacer una opción definitiva, más que la habilidad para solucionarlos, así como la prontitud para cambiar de dirección), el juicio diferido (primero penetrar y comprender reservándose la valoración y el juicio para más adelante) y pensar en términos contrapuestos (mirar al mismo tiempo en dos sentidos contrarios)..

Unidad de lo cognoscitivo y lo afectivo en cada sesión de atmósferas creativas. Cuando se está trabajando el pensamiento creativo y reflexivo se parte siempre de que la actividad lúdica que se esté realizando va a movilizar los recursos afectivos e intelectuales de la persona que esté ejercitando en ese momento la misma.

Ampliar la capacidad o habilidad para plantear o identificar problemas; fortalecer elementos comunes a los grados de creatividad como la inteligencia, la persistencia, la flexibilidad y la originalidad.

- La creatividad ofrece importantes aportes, pues se nutre del cambio y de la incertidumbre,

- El deseo y el hábito de mirar las cosas más profundamente de como lo hacen los demás,

- Estimular la conversación

- Es necesaria una cierta inteligencia en el campo donde se es creativo; ser persistente, constante o tenaz es un factor decisivo para la obtención de soluciones;

Nos da la clave para comprender que la formación de un creativo exige la originalidad, el desarrollo de la misma, le permitirá al estudiante alejarse de los estereotipos de la actividad, desarrollar su imaginación y la intuición para encontrar lo nuevo, entendido no solo, como un producto acabado, como algo ya concluido, sino como la capacidad resultante de esa nueva concepción que le permite adoptar diferentes posturas ante la solución de un problema. Resultando así un aprendizaje significativo y desarrollador.

Otra problemática que incrementa la incapacidad reflexiva, está dada en la respuesta que los docentes que impartimos cursos a distancia recibimos de los alumnos

$\mathrm{Al}$ respecto deseo compartir una experiencia, durante todo el año 2011 he dictado un curso de Creatividad y Comunicación para una empresa cuyos destinatarios eran jóvenes que atendían pacientes con problemas oncológicos.

Los ejercicios de creatividad permitieron, rápidamente disipar, que la problemática comunicacional de la empresa no radicaba en el tipo de paciente que atendían, sino en las dificultades que atraviesa toda organización para comunicarse.

Pero he aquí lo interesante, realicé tres cursos presenciales con 20 participantes cada uno, y unos catorce cursos a distancia en diversas provincias argentinas.

Resultados: La producción de los cursos presenciales era más rica, fluida y con alto grado de reflexión. En los cursos a distancia me he encontrado muchas veces dando clases magistrales, reiterando conceptos, escuchando varias veces frases como "No se me ocurre ninguna idea" “¿Pero cómo hay que hacerlo?” Cuando la consigna era muy clara.

Solo el hecho de estar frente a un computador coloca al alumno en una posición mucho más receptiva, esperando todo de la cosa, esperando que el Otro le resuelva a la manera de Google, todos sus interrogantes.

Entonces, creo que toda la posibilidad de dictar clases y cursos a distancia que son muy positivos porque quizás de otro modo no podrían efectuarse, por lejanos u onerosos, inhiben, solo por ser a distancia. Perdemos la maravillosa posibilidad de hacer feeling de percibir ese ida y 
vuelta, de estar allí, parafraseando a Niko Teodorakis "En carne tibia".

Supongo que ante la vasta oportunidad de aprendizaje, los modelos tradicionales convivirán con los nuevos paradigmas, proporcionando un espectro de oportunidades de aprendizaje, las transiciones de estudiante a aprendiz, de profesor a diseñador, entrenador, consultor, con una mayor capacidad de elegir, diseñar y controlar el ambiente educativo por parte de los estudiantes.

Lentamente las universidades dejarán de estar centradas en los profesores, quienes determinan qué, cómo, dónde y cuándo enseñar y se transformen en instituciones centradas en los estudiantes, quienes tienen mejores opciones y mejor control sobre qué, cómo cuándo y dónde aprender. Desarrollar tanto en nuestros docentes como en los alumnos, una actitud diferente ante la responsabilidad del proceso de enseñanza-aprendizaje. Los alumnos deben tomar poco a poco la responsabilidad de su propio aprendizaje en la medida en que desarrollen una motivación intrínseca en torno a esto.

La autoridad para validar el conocimiento debe partir de un proceso social, dialógico y cooperativo. Para esto es necesario romper con aquellas creencias en las cuales el maestro tiene la verdad acerca del conocimiento a construir y el alumno debe encontrarla bajo el control de este experto; donde el maestro constantemente habla y el alumno escucha y les hace sentir en las clases que está plenamente seguro de lo que enseña, que hay poco que descubrir e indagar en relación con esto.

Quitar los lentes empañados que en determinadas ocasiones no permiten ver la ignorancia. Se vive con lentes empañados cuando año tras año. se repiten las clases tal como se planificaron la primera vez; se termina una licenciatura, maestría o doctorado y nunca más se vuelve abrir un libro de texto o se asiste a un curso de posgrado para el enriquecimiento de la práctica educativa; cuando no se tiene la valentía de decir al alumno qué es lo que se sabe y qué es lo que no. Si se desea limpiar los lentes se debe emplear el conocimiento de manera flexible.

Convertir las aulas en espacios para asombrarnos, experimentar e investigar. Uno de los recursos más importantes y al alcance del educador es la capacidad de asombrarse ante cada comentario reflexivo o creativo de sus alumnos.

Los estudiantes necesitan ser tratados como personas, es decir, tener una buena comunicación cuando están creando o pensando. Los alumnos requieren aprender a escuchar críticamente, tener apertura hacia el juicio del discrepante Además, necesitan aprender a retroalimentarse a sí mismos y a los otros durante un proceso creativo o crítico.

Winicot nos habla de una actividad vital creadora, activa y de una actitud de acatamiento, pasiva dividiendo al mundo en espectadores y protagonistas. Somos protagonistas en nuestro quehacer y espectadores en todo lo demás.

Cuando a Isidore Rabí, premio Nobel de física, le preguntaron qué le había ayudado a ser científico, respondió: "Al salir de la escuela, todas las otras madres judías de Brooklyn preguntaban a sus hijos: ¿Qué habéis aprendido hoy en la escuela? En cambio mi madre decía: Izzy, ¿te has planteado hoy alguna buena pregunta?" (Rabí, 1960, p. 78).

Dice el filósofo Baruj Spinoza: "Toda acción creadora se acompaña de placer, pues en la verdadera actividad, en la realización de sí mismo debe experimentar el hombre el sentimiento de que alcanza su perfección mayor, un sentimiento de alegría" (Spinoza, 2006).

"El que tiene una idea verdadera sabe muy bien que la idea verdadera incluye la máxima certidumbre, y de ninguna manera puede dudarlo , sino tendría que creer que la idea es una cosa muda, como un retrato en un lienzo, y no un modo del pensamiento, es decir del entendimien- 
to mismo". "De todo esto se deduce que no nos esforzamos por nada, ni queremos, anhelamos o codiciamos cosa alguna porque la juzgamos buena, sino por el contrario, la juzgamos buena porque nos esforzamos por ella, la queremos, anhelamos y codiciamos". (Spinoza, 2006). La simplicidad en nuestra vida solamente se da cuando finalmente logramos entender aquellas pocas reglas importantes que determinan cómo funcionan las cosas.

Esas reglas existen y se dan en la naturaleza, se hallan allí presentes esperando a que decidamos buscarlas. Es inherente, pertenece a la naturaleza de las cosas que sean simples. La complejidad se deriva sólo de nuestra incapacidad de comprensión, nuestra ignorancia, o nuestra dificultad para explicar y comunicar lo que pensamos.

Para concluir agregaré un pensamiento de James J. Duderstadt, en su libro Una Universidad para el siglo XXI (2010).

Nuestro mundo está atravesando un nuevo periodo de dramático cambio social, quizás tan profundo como los de otros tiempos, tales como el Renacimiento y la Revolución Industrial, con la diferencia de que estas duraban siglos y hoy solo duran algunos años. Vivimos en una era de aceleración y cambios que nos dejan sin aliento, y si la educación fue más simple, nuestro mundo fue más simple también La característica más previsible de la sociedad moderna es la falta de previsión, ya no creemos que el mañana sea muy parecido al presente (Duderstadt, 2010).

De manera que, las universidades deben encontrar maneras de mantener los aspectos más preciados de sus valores esenciales, mientras descubren nuevos modos de responder con vigor a las oportunidades de un mundo de cambios constantes y veloces.

\section{Referencias Bibliográficas}

Diario Clarín (29 de diciembre de 2011). Para hablar los jóvenes utilizan solo 240 palabras. Duderstadt, J. (2010). Una Universidad para el siglo XXI. Buenos Aires: UP Colección de Educación Superior.

Rabi, I. (1960). Mi tiempo y mi vida como físico. Barcelona: Gedisa, p. 78.

Spinoza, B. (2006). Tratado de la reforma del entendimiento. Buenos Aires: Editorial Cactus. Disponible en: Ediciones El Aleph www.libroteca.net/Descargando.asp?tam=231.07\&archivo...

\section{Bibliografía}

Diario El Comercio. Disponible en: http://www.elcomercio.com/tecnologia/internet-limita-ca pacidad-reflexiva_0_514148621.html.

Diario Clarín (29 de diciembre de 2011). Para hablar los jóvenes utilizan solo 240 palabras.

Boden, M. A. (1994). La mente creativa. España: Gedisa.

Davis, G.; Scott, J. (1989). Estrategias para la creatividad. Buenos Aires: Paidos.

De Bono, E. (1995). El pensamiento creativo. Paidos empresa. 
(1971). Lateral Thinking for Management, Maidenhead, England, McGraw- Hill, London: Penguin.

De Prado Diez, D. (1997). Manual de activacion Creativa. Santiago de Compostela.

Duderstadt, J. (2010). Una Universidad para el siglo XXI. Buenos Aires: UP Colección de Educación Superior.

Dyer, W. (1984). El cielo es el límite. México: Grijalbo.

Guerrero, A. H. (1989). El ateneo, Curso de creatividad. Buenos Aires : El Ateneo.

Nachmanovitch, S. (2006). Free play. Paidos.

Pavlovsky, E. (2007). Espacio y creatividad. Galerna.

Rabi, I. (1960). Mi tiempo y mi vida como físico. Barcelona: Gedisa, p. 78.

Sagan, C. (1989). La persistencia de la memoria, Serie Cosmos episodio 11. Carl Sagan Productions Inc-Videovisa (Videocassette, $52 \mathrm{~min}$ ).

Spinoza, B. (2006). Tratado de la reforma del entendimiento. Buenos Aires: Editorial Cactus. Disponible en: Ediciones El Aleph www.libroteca.net/Descargando.asp?tam=231.07\&archivo...

Villegas Martínez, F. (1985). Como desarrollar la creatividad gerencial. México: Ed. Pac.

\section{Bibliografía Complementaria}

Amabile, T. (1983). The social psychology of creativity. Nueva York: Edit. Springer-Verlog. Anaya. Págs. 155-169.

Ausubel, D., Novak J., Hanesian H. (1983). Psicología Educacional. Un punto de vista cognitivo. México: Ed. Trillas.

Bavelas, J. y Lee, E.. (1986). Effects of goal level on perfomance: A trade of quantity and quality. Canadian Journal of Psychology, Vol. 32 no. 4, Toronto.

Beihler, R. y Snowman, J. (1990). Specifying what is to be learning. Psychology applied to teaching. Boston: Houghton Miffing Co. Págs. 265-311.

Bloom, B. (1973). Taxonomía de los objetivos en educación. Buenos Aires: El Ateneo. Págs. 127-131.

Boirel, R. (1961). Theorie generale de l'invention. Paris: Press Universitaires.

Bruner, J. (1980). La elaboración del sentido. Barcelona: Ed. Paidós.

Clark, M. (1992). Perplexity and knowledge: an inquiry into the structures of questioning. Bélgica: Ed. The Hague.

Coll, C. (1991). Aprendizaje escolar y construcción del conocimiento. Barcelona: Ed. Paidós.

Corral R. (1983). El estudio de la memoria en la psicología cognoscitiva contemporánea. Ed. Univ. Habana.

Csikszentmihalyi M. (1990). The domain of creativity. En: Theories of creativity. (Runco and Albert. Comps.). California: Edit. Sage Publications Inc.

Csikszentmihalyi, M. y Getzels, J. (1970). Concern for discovery: an attitudinal component of creative production. Journal of Personality and Social Psychology, Washington, vol. 38.

D'Angelo O. (1998). Desarrollo Integral de los Proyectos de Vida en la Institución educativa. (PRY CREA IV). La Habana: Ed. PRYCREA.

(1996). El desarrollo personal y su dimensión ética (PRYCREA III ). La Habana: Ed. PRYCREA. Dewey J. (1929). The quest for certainty. New York: Ed. Putma.

Einstein, A. e Infeld, L. (1938). The evolution of physics. New York: Editorial Simon and Schuster. 
Feldman D., Csikszentmihalyi M., Gardner H. (1995). Changing the world-A Framework for the study of Creativity. Westport, Connecticut, London, USA: Praeger Publishers.

Flavell J. (1979). Metacognition and cognitive monitoring: new area of cognition development inquiry. American Psychologist. Washington. Vol. 34.

Freire, P. (1987). Pedagogía de la liberación. Sao Paulo: Editora Moraes.

Gagné, R. y Briggs, L. (1990). Definición de los objetivos de la ejecución. La planificación de la enseñanza. México: Trillas. Págs. 91-113.

Gimeno Sacristán. J. (1985). Teoría de la enseñanza y desarrollo del currículum. Salamanca.

González Valdés, A. (1982). La motivación y la eficiencia de la personalidad. Rev. Santiago, Santiago de Cuba: Univ. Oriente, no. 48.

Creatividad en la industria. Informe Centro de Investigaciones Psicológicas y Sociológicas (CIPS). (1984). Estudio de casos sobre innovadores de alto y bajo rendimiento creador.

Goodman, K. (1994). Lenguaje integral. Ontario: Ed. Scholastic TAB Publications Ltd.

Labarrere Sarduy A. (1994). Pensamiento: análisis y autorregulación en la actividad cognoscitiva. México: Ed. Angeles S. A.

Leontiev A. N. (1981). Actividad, Conciencia y personalidad. La Habana: Ed. Pueblo y Educación. Lipman M. (1991). Thinking in education. Philadelphia: Temple Univ. Press.

MacClelland, D. Y Atkinson J. (1982). The acievement motive. New York: Ed. Apple Century Crofts.

Moreira A. (1996). Aprendizaje significativo. Fundamentación, teoría y estrategias facilitadoras. Ed. Univ. Federal do Rio Grande do sul.

Novak J., Gowin D. (1988). Aprendiendo a aprender. Barcelona: Ed. Martínez Roca.

Summary: College students find it increasingly difficult to analyze, understand, make relations and synthesize. Students consider every content on the internet as a truth and also they valid it without a critical spirit, placing themselves in a comfortable viewers position. University professors should change the way of teaching, ceasing to be the big Other for students. The creativity of university students is a professional challenge and an opportunity for tremendous personal growth of human value.

Key words: communication - creativity - knowledge - teaching.

Resumo: Os estudantes universitários encontram cada vez maiores dificuldades em analisar, compreender, relacionar e sintetizar. Os alunos tomam por certo tudo o que está na Internet e o dão por válido sem um espírito crítico, se põem numa posição de cômodos espectadores. Os professores universitários deveriam mudar nossa maneira de exercer docência, deixando de ser esse grande Outro que nos confere o aluno. A criatividade dos alunos universitários representa um reto profissional e uma possibilidade de crescimento pessoal de enorme valor humano.

Palavras chave: comunicação - conhecimento - criatividade - docência. 